\title{
AERODYNAMIC STUDY OF SLOTTED FLAP FOR NACA 24012 AIRFOIL BY DYNAMIC MESH TECHNIQUES AND VISUALIZATION FLOW
}

\author{
Emad Qasem Hussein ${ }^{1}$, Haider Nadhom Azziz² ${ }^{\text {, Farhan Lafta Rashid }}{ }^{3}$
}

\begin{abstract}
Slotted flap is one of high lift devices. It considered as a moving part of the airfoil which is used as a control instrument in a form of elevator, rudders and ailerons. The main focus of work is to investigate the effect of flap chord, gap and overlap on aerodynamic characteristic of NACA 24012 airfoil. The model was tested with 20\% C, $30 \% \mathrm{C}$ and $40 \% \mathrm{C}$ single slotted flaps at zero angle of attack. The dynamic mesh and user defined function is applied to control the flap distance with respect to wing at any position. The simulation was done by solving the governing equations (Continuity, Reynolds Averaging Naveir- Stokes and Energy Equation) in 2-D using Fluent analysis at Reynolds number of $3.1 \times 10^{6}$.

Based on the results presented, larger increment of lift coefficient is obtained with the larger flap chord, but this increase is accompanied by a drag penalty. Furthermore, the loss of lift coefficient associated with larger extending flap at $3 \% \mathrm{C}$ had a very detrimental effect on the attainable lift coefficient. The simulation result also shows that an optimum gap is $1 \% \mathrm{C}$ in order to derive the maximum lift capability from the flap model. The code is validated against field measurements to show how close the CFD model simulates the reality.
\end{abstract}

Keywords: Aerodynamic Characteristic, Slotted Flap, Dynamic Mesh, CFD, Angle of Attack

\section{INTRODUCTION}

Flap is a high lift device type used to increase the aircraft wing lift at a specific airspeed. The flaps are movable element permits the aircraft pilot to change the aerodynamic characteristics and geometry of the wing section to control the airplane motion in order to improve the performance in some desired aircraft manner [1].The devices of high lift can be applied to the airfoil trailing edge, as shown in Fig. (1).

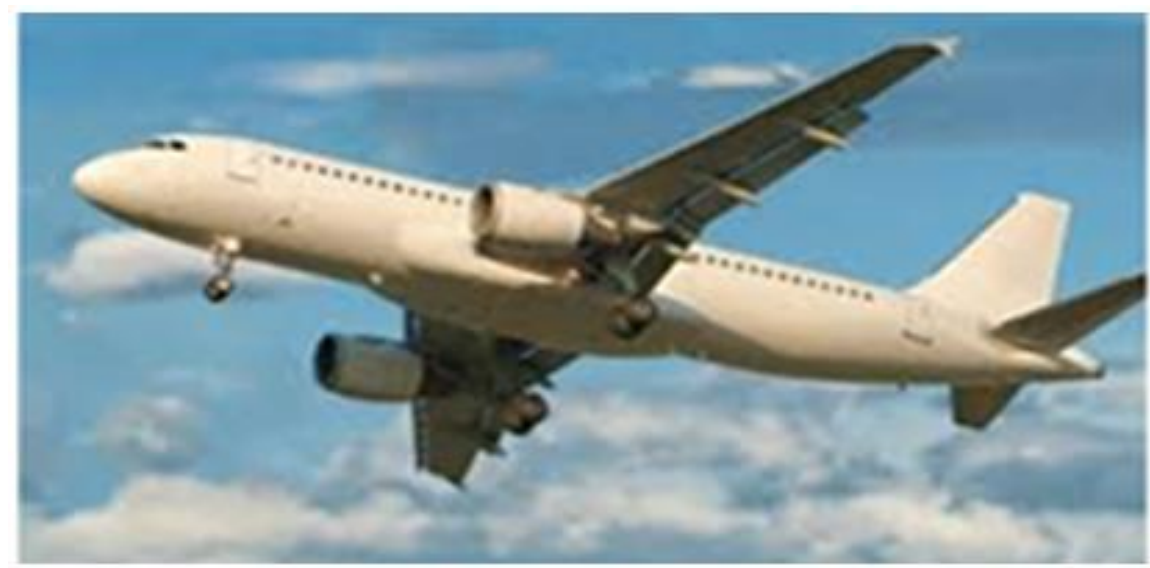

Figure 1. Aircraft wing with single slotted flap [2]

Lift coefficient have a significant increase when the chord is affected by the camber added well aft. Air of high energy from the lower surface is ducted to the upper surface of flap. This high energy air will accelerate the boundary layer of upper surface and delays separation of airflow to some higher lift coefficient [3].The slotted flaps lift increment is a result of three main factors: The first is the camber effective change produced by setting down the flap. The second factor is due to the flow through the boundary layer of slot reenergizing, when the slot is designed perfectly and so delaying flow separation from the flap. The third is the effective lifting surface increase due to the rearward movement of the flap [4]. The effect of downstream flap on the immediate upstream main airfoil can be

\footnotetext{
This paper was recommended for publication in revised form by Regional Editor Hamadiche Mahmoud

${ }^{1}$ Department of Mechanical Engineering Department, University of Kerbala, Iraq

2, ${ }^{3}$ Department of Petroleum Engineering Department, University of Kerbala, Iraq

E-mail address: farhan.lefta@uokerbala.edu.iq,engfarhan71@gmail.com

Orcid id: 0000-0001-8643-2143, 0000-0003-4310-0346, 0000-0002-7609-6585

Manuscript Received 03 February 2019, Accepted 8 April 2019
} 
simulated by putting a vortex near the trailing edge such that it lead to a velocity rise on both upper and lower surfaces, it results to a low rise in lift coefficient [5].There are different flab design used with the specific liberty depending on the speed, size and aircraft complexity on which they are to be used [6].

Design of airfoil have a pivotal role in control surface and wing performance for aerospace engineering. The panel method cannot calculate sharp corners in the contour of airfoil. Deflections of positive flap give such an arc automatically in the upper surface of a real wind-turbine blade. A local separation in the real flow, which is responsible for introducing an arc in the theoretical model [7]. Emad et al. [8] presented an aerodynamic heating study on an ogive and conical noses of a fly body using ANSYS Fluent 17.0. The results of study show that the distribution magnitude of internal heat for body nose temperature is directly proportional with attack angle and Mach number. Kaan et al. [9-12] performed measurements for real-time air quality of emissions for three months in Ambarli, Marport Terminal. In their research, critical times of all the emissions are specified between the measured dates using CFD modeling. Iman et al. [13] focused on extend the multifluid descriptions application to specified conditions for the first time using Maxwell and Smoluchowski models. Emad et al. [14] investigated the dynamic and vibration behavior of valve disc in the response to self-excited fluid flow using ANSUS program, when the valve disc starts from it fully opened position.

The CFD (computational fluid dynamics) produces an attractive model of flow over an airfoil. The focus of the current research will be investigations the effect of flap chord, gap and overlap on aerodynamic characteristic of a NACA 24012 airfoil. Finally, several airfoils within the most useful range of shape will investigated to provide data for the various airfoils that may be chosen as most efficient in particular application.

\section{PHYSICAL MODEL}

In this work, the flow field around airfoil is study; the geometry of the bodies was simplified in the CFD model, as shown in Fig. (2) for single slotted flap geometry.

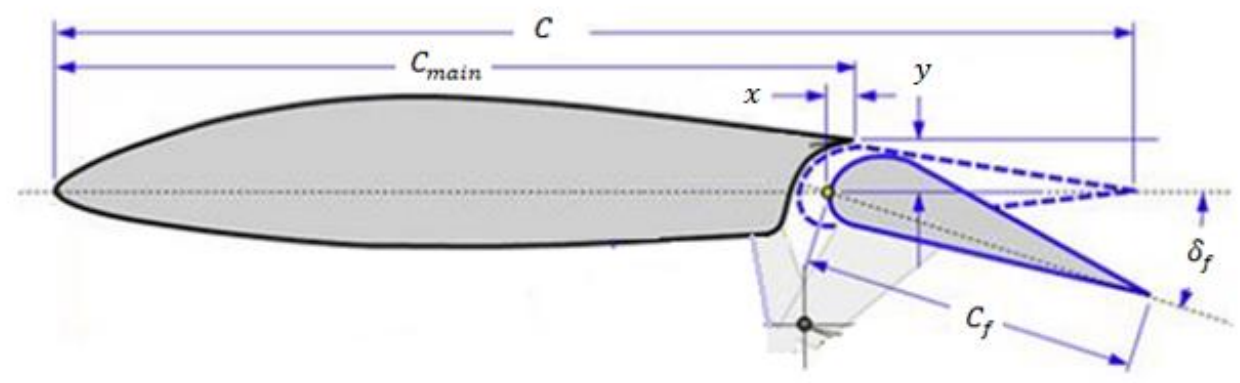

Figure 2. Geometry for single slotted flap [15]

The airfoil will be modeled at zero attack angle with angle variation of flap from $\delta_{f}=0^{\circ}$ to $\delta_{f}=40^{\circ}$, the numerical simulation was performed for three different length of slot flap ( $C_{f}=20 \% C, 30 \% C$ and $40 \% C$ ), whose length is expressed as airfoil chord percentages.

\section{Methodology Adapted}

In the present case, ANSYS Fluent was used to solve Reynolds Averaged Navier Stokes equations (RANS), these equations are based on the fundamental concepts of conservation of mass, energy and momentum [16, 17].

\section{Continuity Equation}

$$
\frac{\partial \rho}{\partial t}+\nabla \cdot(\rho \bar{u})=0
$$

The first term in Eqn.(1) represents the change rate of mass in a control volume element and the second term represents the change rate in mass due to convection. 


\section{Momentum Equation}

$$
\frac{\partial}{\partial t}(\rho \bar{u})+\nabla(\rho \bar{u} \bar{u})=-\nabla P+\nabla(\overline{\bar{\tau}})+\rho \bar{g}
$$

The first term in Eqn.(2) represents the change rate of momentum into volume element and the second term represents the change rate in momentum due to convection, the third is the change rate due to pressure forces, the fourth represents the change rate due to viscous forces and the last is the change rate due to gravitation.

\section{Energy Equation}

$$
\rho c_{p}\left(\frac{\partial \mathrm{T}}{\partial \mathrm{t}}+\mathrm{v}_{x} \frac{\partial t}{\partial x}+v_{y} \frac{\partial T}{\partial y}=\lambda\left(\frac{\partial^{2} T}{\partial x^{2}}+\frac{\partial^{2} T}{\partial y^{2}}\right)\right.
$$

Eqn.(3) represents the energy equation which is required whenever heat transfer or pressure work is present in the flow. For our case, the flow is assumed to be compressible and constant viscosity.

\section{Turbulence Modeling}

For slotted flap investigation at high Reynolds number $k-\omega$ RNG model is chosen as verified by turbulences model dependency studies by Krishnaswamy et.

For $k-\omega$ RNG Turbulence model. The turbulence kinetic energy, $\mathrm{k}$ and its rate of dissipation $\varepsilon$, in $k-\varepsilon$ RNG turbulence model can be found from the following equations:

$$
\begin{gathered}
\frac{\partial}{\partial t}(\rho k)+\frac{\partial}{\partial x_{i}}\left(\rho k u_{i}\right)=\frac{\partial}{\partial x_{j}}\left(\alpha_{k} u_{\varepsilon} \frac{\partial k}{\partial x_{i}}\right)+G_{k}+G_{b}+\rho \varepsilon-Y_{M}+S_{k} \\
\frac{\partial}{\partial t}(\rho \varepsilon)+\frac{\partial}{\partial x_{i}}\left(\rho \epsilon u_{i}\right)=\frac{\partial}{\partial x_{j}}\left(\alpha_{k} u_{\varepsilon} \frac{\partial \varepsilon}{\partial x_{i}}\right)+G_{1 \varepsilon} \frac{\varepsilon}{k}\left(G_{k}+C_{3 \varepsilon} C_{b}\right)-C_{2 \varepsilon} \frac{\varepsilon^{2}}{k}-R_{\varepsilon}+S_{\varepsilon}
\end{gathered}
$$

In equations (4 and 5), $G_{k}$ is the turbulence kinetic energy generation result from the mean velocity gradients, whereas $G_{b}$ is the turbulent kinetic energy generation result from buoyancy, $Y_{m}$ is the fluctuating dilation contribution in compressible turbulence to overall dissipation rate. $\alpha_{k}$ and $\alpha_{\varepsilon}$ are the inverse Prandtl numbers for $k$ and $\varepsilon$, respectively. Value of model constants has been derived analytically by the RNG theory.

\section{PROBLEM SPECIFICATION}

In an external flow over an airfoil with flap, we have to define a far- filed boundary and mesh the region between the body geometry and boundary. The geometric model consists of C-type domain with radius 10 times length of airfoil which is located in the middle of domain, to ensure there is no reflecting influences from boundaries. Fig.(3) shows the grid used for solving the flow over an airfoil [18].The computational domain quality will plays an important role in the stability and accuracy of the calculation. Therefore to control the mesh quality a number of criteria can be evaluated in Fluent such as maximum cell skewness and maximum aspect ratio.

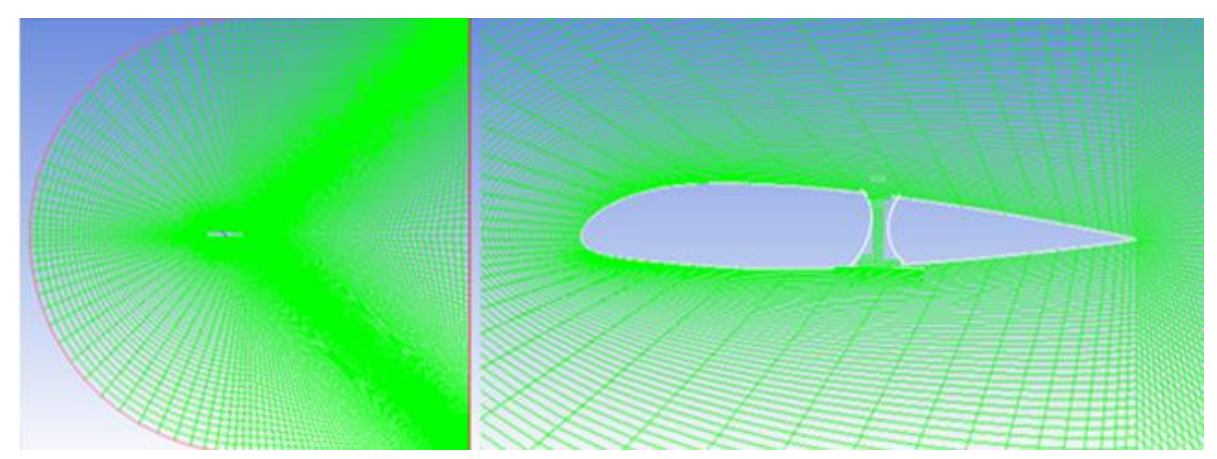

Figure 3. Mesh generation of the 1 NACA24012 airfoi with flap 
After completing the meshing of the model, it was applying ANSYS Fluent 17.2 and the parameter for the simulation was established. A pressure far-filed boundary condition was imposed on the domain outer boundaries. The $k-\omega$ turbulence models were used given its suitability for modeling flows separated regions. The pressure based simple algorithm was used for pressure- velocity coupling in addition to a least-square cell based discretization schema and a second order upwind scheme was used for the momentum and turbulence equations discretization. The model type solver pressure based with viscous model as Spalart-Allmaras. Ideal gas law to determine the air density, while Sutherland's was used to calculate the air viscosity. The turbulence intensity was set to $1 \%$ with turbulence length scale being the same as the airfioal chord.The Reynolds number based on the chord length and free stream flow condition was $3.1 \times 10^{6}$ and the Mach number was 0.135. All simulation were run until both the lift and drag coefficients converged and all residuals dropped below $1 \times 10^{-6}$.

\section{Dynamic Mesh}

The model of dynamic mesh in Fluent may be adopted to simulate flows where the domain shape is a function of time due to motion on the boundaries of domain. Methods of mesh motion are found in Fluent for updating the mesh in the regions of deforming subjected to the motion namely, smoothing, dynamic layering and local remeshing methods. The option of dynamic mesh is used during transient simulation to prevent the formation of negative cell volumes due to mesh quality deterioration and maintain a high mesh quality. The requirements of a dynamic simulation are description of the boundary motion and an initial mesh [19, 20]. In the current study, the defection of the flap is described by a UDF (User Define Function). A UDF is a function written in C-programming language scheme can be dynamically linked with the Fluent. UDF's are executed as compiled function in Fluent. The UDF code defines the mesh motion through dynamic zones, which correspond to the center of gravity motion of airfoil with flap. The choice of compilation or interpretation is based on the type of macro used and is specified in the supplied UDF manual. The dynamic meshing macros all require compiling, which can be accomplished through the Fluent Graphical User Interface (GUI) menus.

\section{Grid Independency Study}

The mesh size influence on the solution results must be investigated for the first step of accomplishing a CFD simulation. For more accurate approach, a more nodes are needed, and using further nodes will escalates the requisite computational time and computer memory. In order to determining the suitable number of nodes, it can be done by increasing the nodes number until the mesh being fine. Fig. (4), presents the coefficient of drag variation with grid cells number at flap deflection angle of $20^{\circ}$

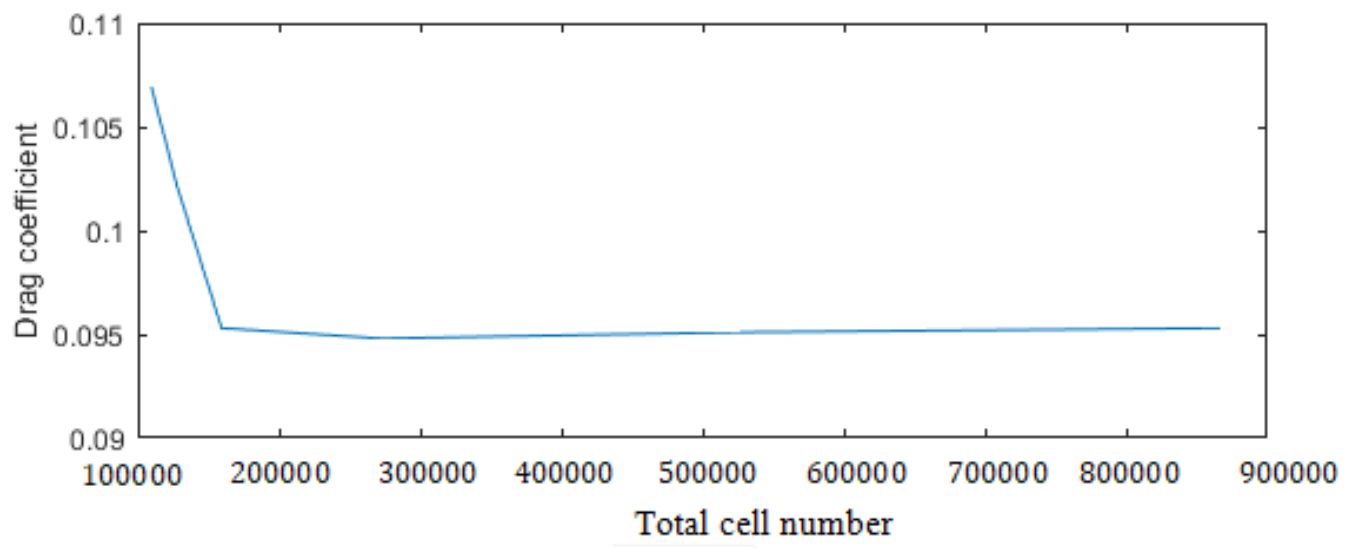

Figure 4. Grid independency study for drag coefficient at flap angle $20^{\circ}$

\section{RESULTS AND DISCUSSION}

Results of the previously described analysis are presented in this section. The simulation was carried out using Fluent programs for different length of the slot flap. The pressure contour over NACA 24012 airfoil at zero angle of attack with flap deflected angle $30^{\circ}$ is presented in Fig.(5) and from the plot it is clear that, as flap is 
deflected, causes decrease in velocities and setting up of the pressure beneath the airfoil which simultaneously increases adverse pressure gradient with flap deflection. Therefore, by increasing deflection angle of the flap which leads to increases the pressure over an airfoil even without changing the angle of attack. Due to increase the chamber line of the airfoil.

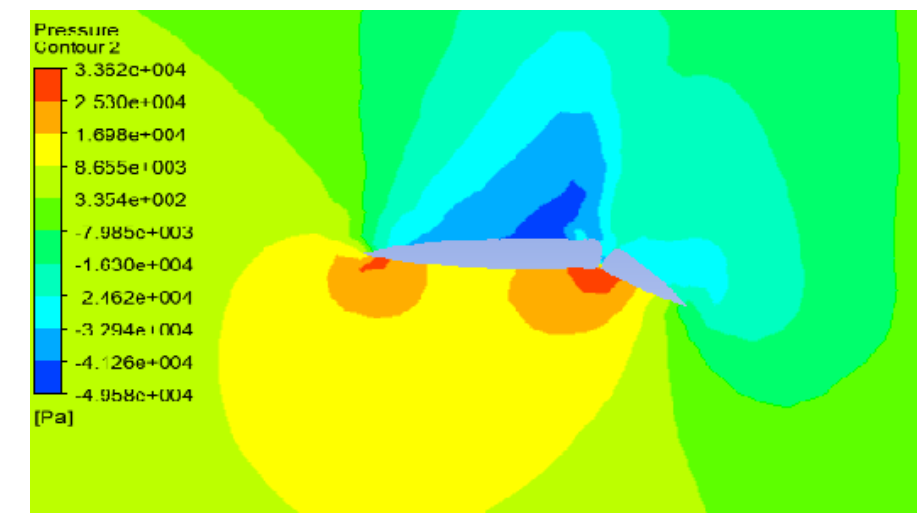

Figure 5. Variation of pressure contour for flap deflection airfoil of $\delta_{f}=30^{\circ}$

The effect of flap chord on the lift coefficient is observed in Fig.(6) at various flap deflection angles. The result data presented for the $\left(C_{f}=20 \% C, 30 \% C\right.$ and $\left.40 \% C\right)$ are reasonably comparable in that the shapes of the slots are generally similar. When a flap chord increase the upper chamber of the airfoil increasing the negative pressure on the top of the airfoil , at the same time they allow a buildup of pressure below the airfoil. From the figure above show that larger increment of lift coefficient $C L$, are obtained with the larger flap chord .Another important point in these analysis it observed that, slight increase in drag coefficient $C D$ as shown in Fig.(7), due to disturbance between the airfoil and flap, which may be valuable pending approximation and landing. Whereas, the measure of the efficiency of the airfoil as a lifting surface is given by the CL/CD ratio, which is seen in Fig.(8).

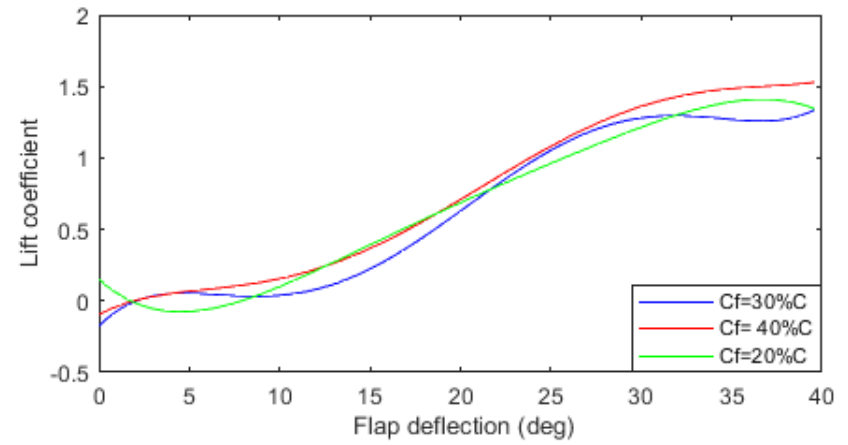

Figure 6. Lift coefficient variation with flap deflection angle at zero attack angle

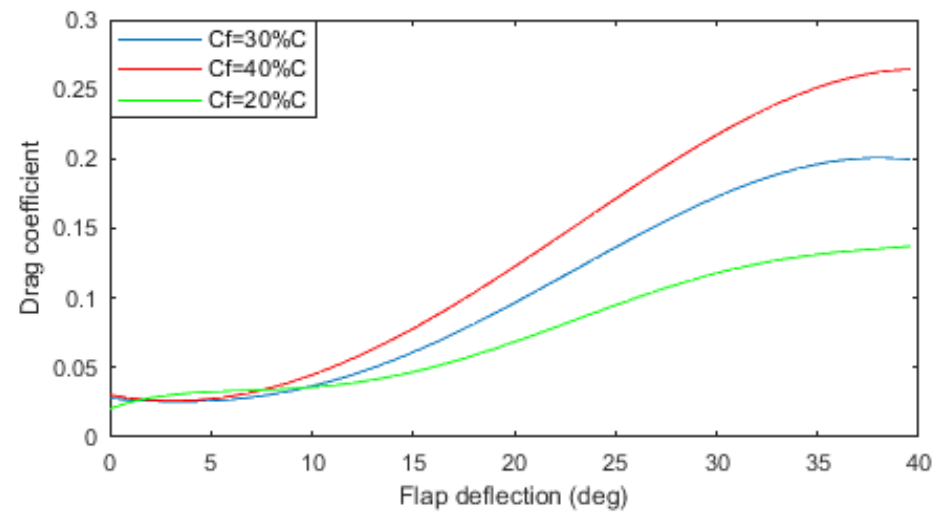

Figure 7. Drag coefficient variation with flap deflection angle at zero attack angle 


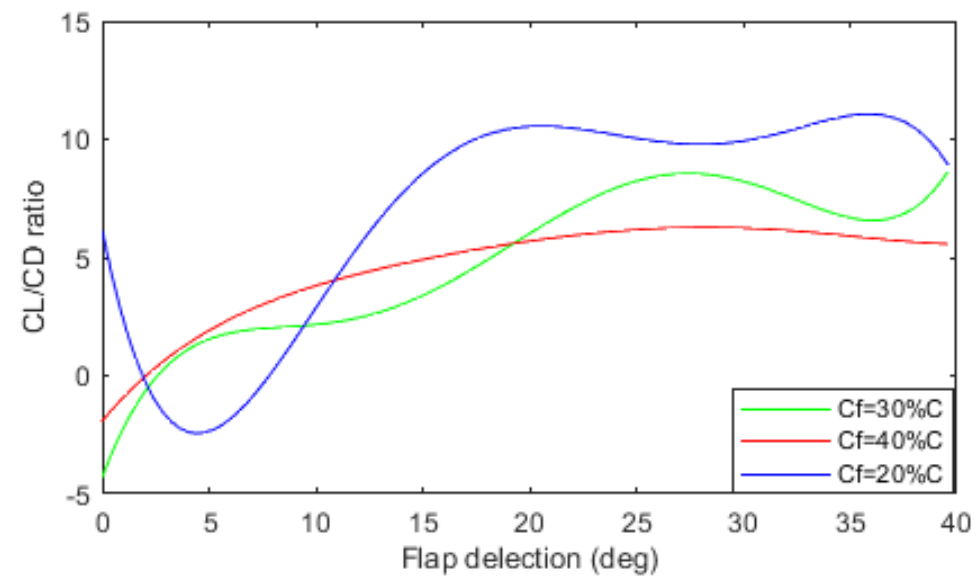

Figure 8. CL/CD ratio variation with flap deflection angle at zero attack angle

The effect of the overlap position between the airfoil and flap $\left(C_{f}=30 \% C\right)$ was studied for three positions in longitudinal axis $(\mathrm{x}=1 \% \mathrm{C}, 2 \% \mathrm{C}$ and $3 \% \mathrm{C})$ and shown in Figs. $(9,10$ and 11$)$. It is seen that firstly in these figures, the maximum value of drag coefficient at extending the flap at $3 \% \mathrm{C}$, whereas, the maximum value of lift coefficient is get at extending the flap at $1 \% \mathrm{C}$. Due to high pressure air from the beneath the airfoil over the flap assisting the airflow keep attached to the flap. A cross the entire chord, lift of the primary airfoil is highly raised when the velocity air leaving its trailing edge is raised. The flap is dominated by viscous effect as boundary layer transition and flow separation. Extending the flap also increases the drag coefficient of an airfoil due to higher induced drag caused by distorted chord lift distribution on the airfoil with flaps extended. Finally, overlap is carefully designed so that the air that flows through the gap keeps the flow on the flap attached even when the airfoil is at high angles of attack.

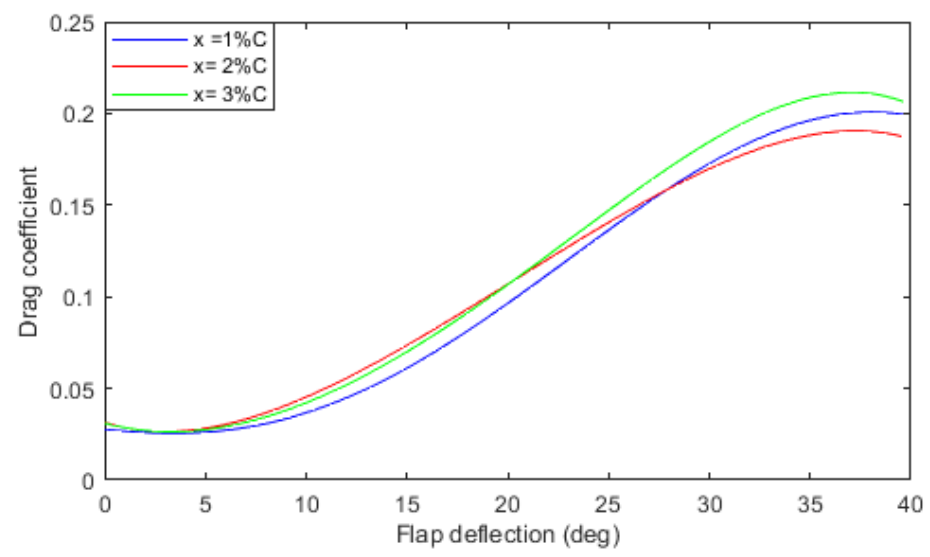

Figure 9. Drag coefficient variation with flap deflection angle at zero attack angle

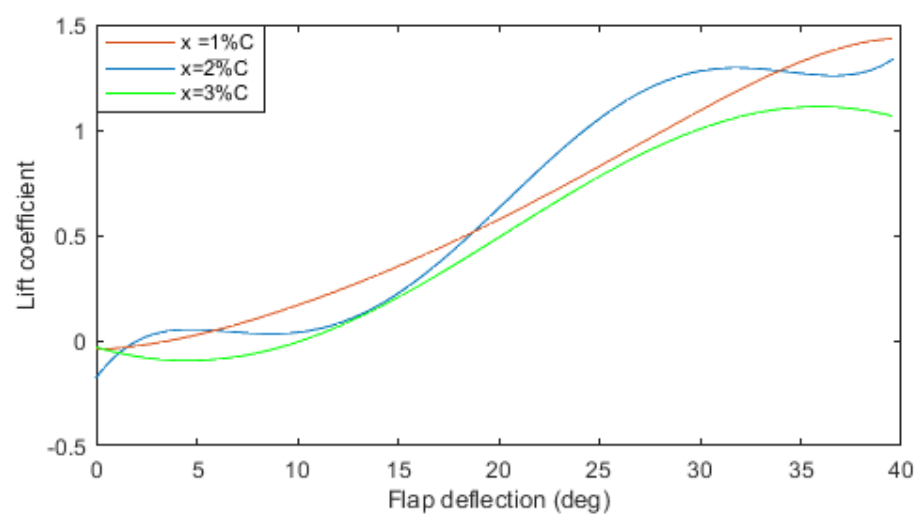

Figure 10. Lift coefficient variation with flap deflection angle at zero attack angle 


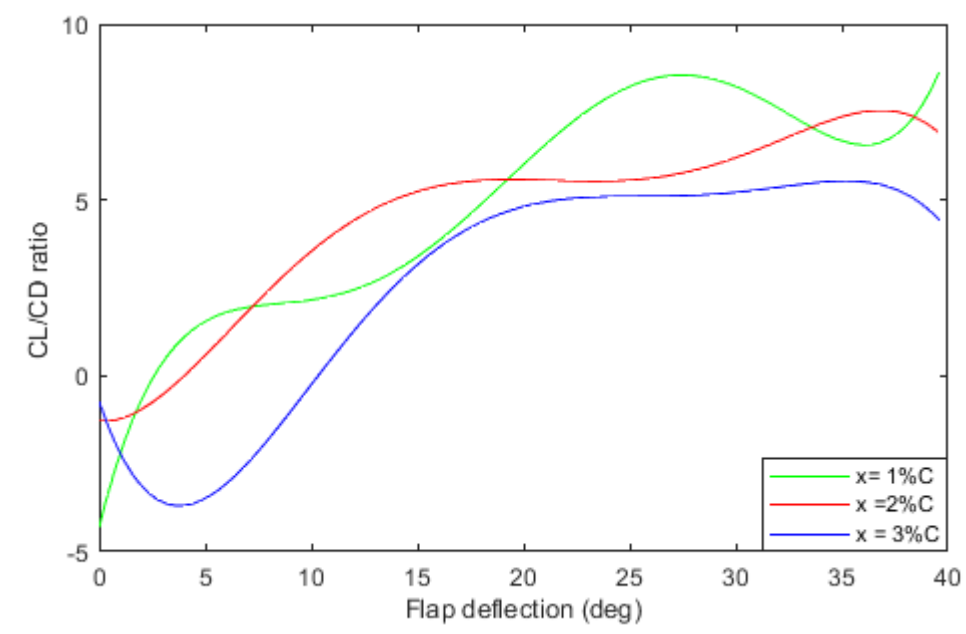

Figure 11. CL/CD ratio variation with flap defection angle at zero attack angle

The effect of the gap between airfoil and flap $\left(C_{f}=30 \% C\right)$ with respect to the airfoil was studied for three positions in lateral axis $(\mathrm{y}=0 \% \mathrm{C},-1 \% \mathrm{C}$ and $1 \% \mathrm{C})$ as shown in Figs. (12 and 13) .It is seen that, the flap is fixed beneath the airfoil trailing edge, it has more drag than other types but is slight effective at creating additional lift coefficient than other type. When, the gap between the flap and airfoil is small and not enough fluid is capable to pass during the slot causing the flap to lose its effect, compared with large of a value. Another important point it show that, the contribution of lift coefficient augmented exceed the drag coefficient increase yielding an augmented CL/CD ratio as shown in Fig.(14), because of a higher CL/CD ratio it gives better take off and climb performance.

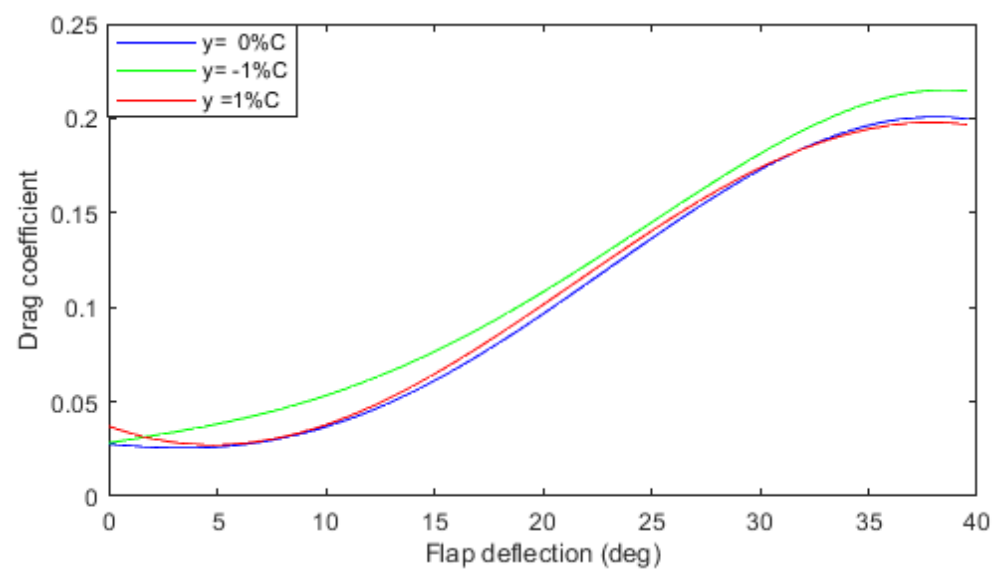

Figure 12. Drag coefficient variation with flap deflection angle at zero attack angle

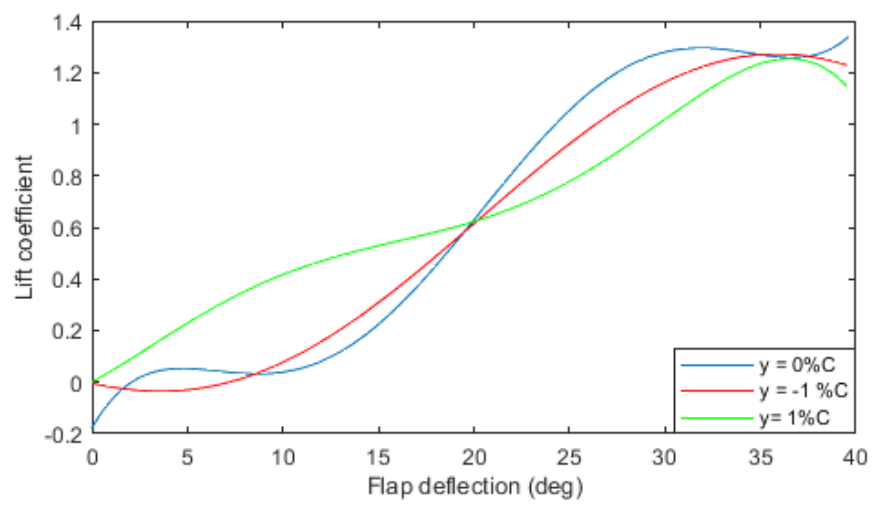

Figure 13. Lift coefficient variation with flap deflection angle at zero attack angle 


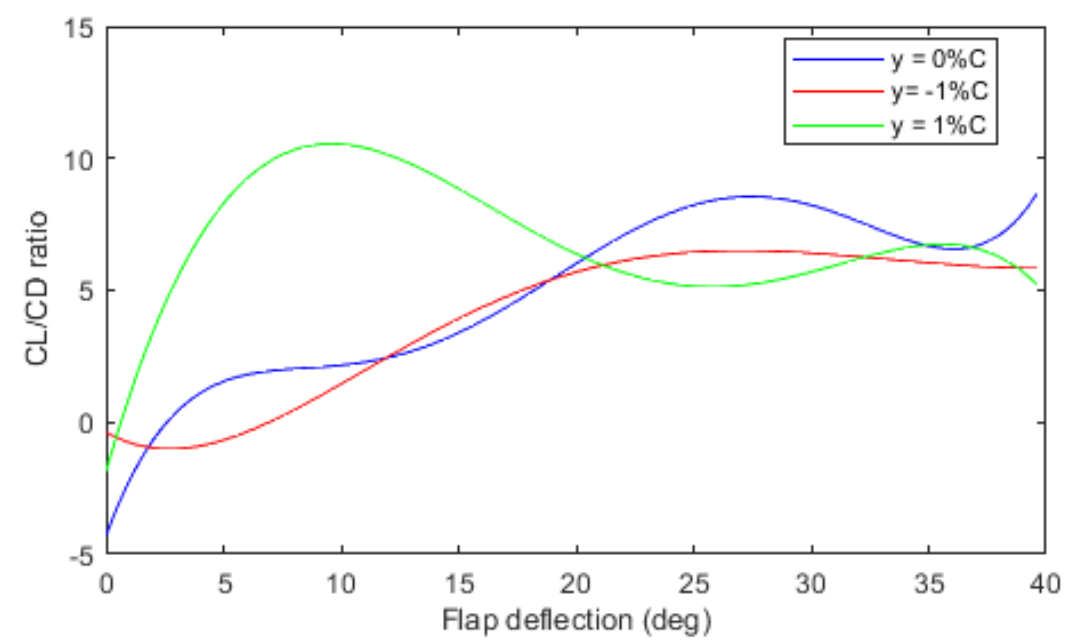

Figure 14. CL/CD ratio variation with flap angle at different gap for zero attack angle

In order to prove the validation of the simulation model. The lift and drag coefficient of the simulation at $R e=3.1 * 10^{6}$ over a wide range of angle of attack have been compared to experimental data obtained from references [21, 22] .Based on the results shown in Figs. (15 and 16). It can be concluded that, the method of CFD modeling and simulating which is used in this work is suitable in calculating flow around airfoil. Also it show that CFD simulations can supply a more accuracy for geometry change investigations such as flap and the maximum discrepant between them is reasonable [23].

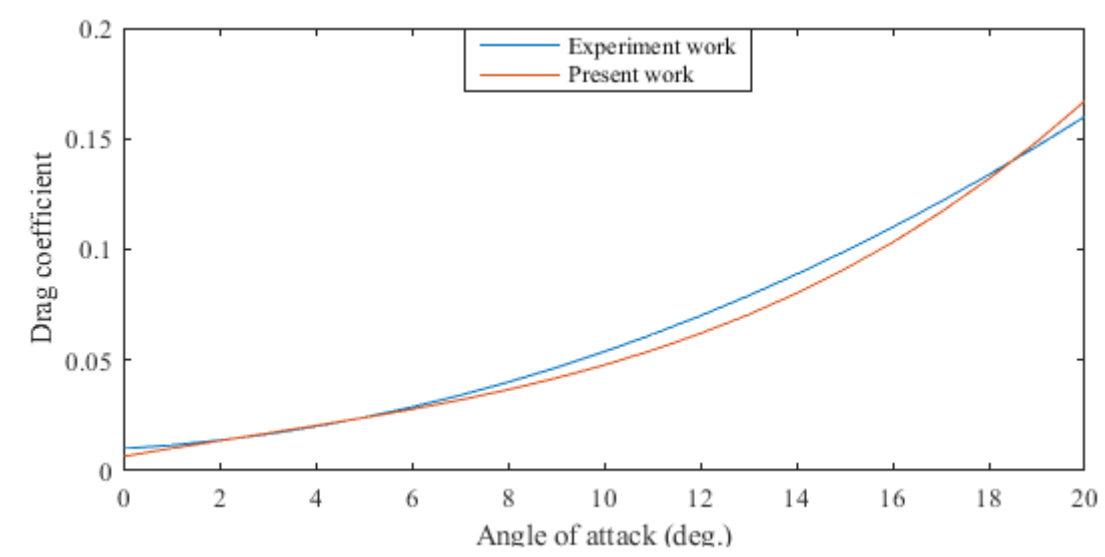

Figure 15. Drag coefficient variation with angle of attack for different technique

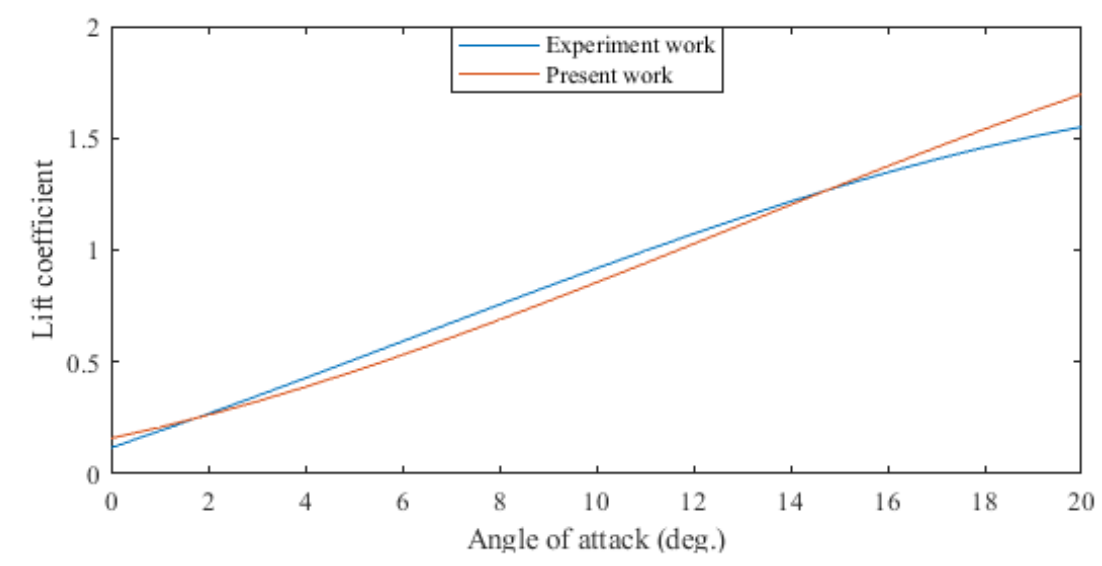

Figure 16. Lift coefficient variation with attack angle for different technique 


\section{CONCLUSION}

The paper deals with investigations of effect of flap chord, gap and overlap on aerodynamic characteristic of the NACA 24012 airfoil. The k-omega RNG models have used with dynamic meshing technique in ANSYS Fluent 17.2. Lift and drag coefficient coefficients and the ratio is analyzed for zero attack angle, drag and lift coefficient are validated for different attack with experimental data. The results show that, the flaps change the pressure distribution around airfoil by changing its chord length and position. Moreover, extending the flap also increases the drag coefficient of an airfoil due to higher induced drag. Finally, the gap size between the airfoil and flap has an influence on the lift and drag coefficient at zero attack angle.

\section{NOMENCLATURE}

\section{C}

$C D$

$C L$

$C_{f}$

$C_{P}$

F

$g$

$t$

P

$T$

$u$

$v$

$x$

$y$

\section{Greek}

$\rho$

$\lambda$

$v$

$\mu$

$\delta_{f}$

chord

coefficient of drag

coefficient of lift

flap chord

heat capacity at constant pressure.

force vector

gravitational acceleration

time

pressure

temperature

flow velocity

kinematic viscosity

coordinate in longitudinal axis

coordinate in lateral axis

\section{REFERENCES}

[1] Norbert R. Kluga . A Study of Flap Management an Analysis of the Consequences of Flap Management and a Search for Possible Causes. JAAER 1991; 1(3): 10-25.

[2] Foster D.N., Irwin H.P. and Willam B.R. The Two Dimensional Flow around a Slotted Flap. London. Repots and Memoranda 1971; 3681: 1-69.

[3] Michael Damianov Todorov. Aerodynamic Characteristics of Airfoil with Single Slotted Flap for Light Airplane Wing. Technical University of Sofia 2015.

[4] Bakhtian N. M. and Babisky H. The Low Reynolds Number Aerodynamics of Leading Edge Flaps. 45 AIAA Aerospace Sciences Meeting and Exhibit 2007:1-13.

[5] Ma, R., \& Liu, P. Numerical Simulation of Low Reynolds-Number and High-Lift Airfoil. In Proceedings of the World Congress on Engineering 2009; 1(2).

[6] Gamboa, P., Vale, J., P. Lau, F. J., \& Suleman, A. Optimization of a Morphing Wing Based on Coupled Aerodynamic and Structural Constraints. AIAA Journal 2009; 47(9): 2087-2104.

[7] Somers D.M. Effect of Flap Deflection on Section Characteristics of S813 Airfoil. State College Pennsylvania 2005; NREL/SR-500-36335.

[8] Emad Qasem Hussein, Farhan Lafta Rashid, Haider Nadhom Azziz. Aerodynamic Heating Distribution for Temperature Prediction of Fast Flying Body Nose Using CFD. Journal of Advanced Research in Fluid Mechanics and Thermal Sciences 2019; 64 (2): 183-195. 
[9] Kaan Ünlügençoğlu , Ahmet Yurtseven, Fuat Alarçin. Shipping Emission dispersions on the Port of Ambarli via CFD Modelling. Journal of Thermal Engineering 2020; 6(2):1-14.

[10] Shankar, S., Astagi, H. V., Hotti, S. R., Hebbal, O., Dixit, M., Kaushik, S. C., Sharifishourabi, M.. Effect of Exhaust Gas Recirculation (EGR) on Performance, Emissions and Combustion Characteristics of a Low Heat Rejection (LHR) Diesel Engine Using Pongamia Biodiesel. Journal of Thermal Engineering 2016; 2(6): 1007-1016.

[11] Hotti, S., \& Hebbal, O. Biodiesel production and fuel properties from non-edible Champaca (Michelia champaca) seed oil for use in diesel engine. Journal of Thermal Engineering 2015; 1(1): 330-336.

[12] D. Khan and Z. Gul. Performance Map Measurement, Zero-Dimensional Modelling \& Vibration Analysis of A Single Cylinder Diesel Engine. Journal of Thermal Engineering 2017; 3(4):1391-1410.

[13] Iman Zahmatkesh , Homayoun Emdad , Mohammad M. Alishahi. Multifluid Description of Rarefied Gas Mixture Flows. Journal of Thermal Engineering 2020; 6(3): 405-421.

[14] Emad Qasem Hussein, Basim Raheem, Farhan Lafta. Fluid Structure Interaction of Non-Return Valve Using CFD. Journal of Mechanical Engineering Research and Developments 2020; 43 (7):137-148.

[15] Dino Florjancic. Improved Design of a High Lift System for General Aviation Aircraft. Master Thesis, Delft University of Technology 2015.

[16] Withman, N., Sparks, R., Ali S., and Ashworth J. Experimental Investigation of Slotted Airfoil Performance with Modified Slot Configurations. AIAA 2006.

[17] Van Dam CP. The Aerodynamic Design of Multi-Element High-Lift Systems for Transport Airplanes. Progress in Aerospace Sciences 2002; 38: 101-144.

[18] Fluent Inc. FLUENT 6.0 User's Guide 2001; 5, USA.

[19] ANSYS Inc. Fluent 2010: http://www.ansys.com/products/fluid-dynamics/fluent/

[20] Ryne Derrick Rademacher. Computational Analysis of a Wing Oscillation. Master Theses, West Michigan University 2012.

[21] Eastman N. , Jacons, M. Pinkerton. Tests of Related Forward Camber Airfoil in the Variable Density Wind Tunnel. Report No. 610 1996: 697-731.

[22] Ira. H. Abbott. Theory of Wing Sections Including A Summary of Airfoil Data. ISBN 0-486-605868, New York 1958.

[23] Muhannad Al-Waily, Nibras A. Aziz Al-Roubaiee, Emad Q. Hussein. Mechanical behavior investigation for hip joint with inclination angle influence by manufacturing and design simulator instrument machine. International Journal of Energy and Environment 2020; 11(1): 47-60. 